\title{
Velocity Adjustable Wind Turbine Simulator based onActual Wind Generator for Laboratory Use
}

\author{
Napat Watjanatepin ${ }^{\# 1}$ SuvinaiSodajaroen $^{* 2}$ \\ ${ }^{\text {\#} S o l a r ~ E n e r g y ~ R e s e a r c h ~ a n d ~ T e c h n o l o g y ~ T r a n s f e r ~ C e n t e r ~(S E R T T) ~}$ \\ Faculty of Engineering and Architecture. \\ ${ }^{1}$ watjanatepin.n@gmail.com \\ ${ }^{1}$ Rajamangala University of Technology Suvarnabhumi Nonthaburi Thailand \\ ${ }^{*}$ Research and Development Institute. \\ ${ }^{2}$ suvinaisodajaroen@gmail.com \\ ${ }^{2}$ Rajamangala University of Technology Suvarnabhumi Nonthaburi Thailand
}

\begin{abstract}
The objective of this research is (1) to design and construct the wind turbine simulator based on the adjustable actual wind speed. (2) To investigate the wind distribution, and (3) tobe applied for testing the power output of the micro-wind turbine in the laboratory. Design and CAD drawing was applied to construct the wind turbine simulator prototype.The 3 phase induction motor with axial fan was used for the wind-generating machine. The wind speed was controlled by frequency converter drive. The anemometer, tachometer, power meter and volt/amp meter was used for wind speed, rotational and electrical data measurement. The 100-watts micro-wind turbine was applied in this study. The results showed that the adjustable wind velocity of the wind turbine simulator was realized by using axial fan with a three phase induction motor driven by an inverter which produced various wind speed at the maximum of $9.33 \mathrm{~m} / \mathrm{s}$. The distribution of air flow always covered the cross section area of the fan blade. The air flow distribution was rather constant at all frequencies. The wind turbine simulator could be applied to test the micro-wind turbine. The generated output power graph obtained from the wind turbine simulator resembled with those of the power curve of the wind turbine's manufacturer. The open-Loop adjustable speed wind turbine simulator has a great benefit for thearchitecture and engineering laboratory use.
\end{abstract}

Keywords:Wind Turbine Simulator, Velocity Adjustable, Micro-wind turbine testing

\section{INTRODUCTION}

Wind energy is an alternative energy that is widely used for electrical energy production around the World. The energy conversion process involves using the wind generator to convert wind energy to electrical energy. The study of the Global Wind Energy Council (GWEC) showed that the total energy produced by wind turbine generator installed globally is $432.9 \mathrm{GW}$.[1] In general, wind turbines will mostly be a horizontal axis type. In the case of small-scale/micro-scale wind turbines, the blades will be fixed pitch angle blade with the generator type being permanent magnet. Their application is intended for stand-alone system, however, some may be connected to low-voltage utility grids. The blades of large-scale wind turbine (WT) are variable pitch angle blades. Most of them are incorporated with synchronous generator [2] and are installed in the wind farm.

Wind turbine simulator (WTS) is important equipment that is used to design wind turbine blade and control strategies, and study the operations of the wind turbine as well as to study the control and monitoring of the wind energy system. Usually, the wind turbine simulator will be adirect coupling of motor and generator. Subsequently, the speed of motor is controlled by an inverter. Eventually, the output of the generator will be connected with the energy convertor to the stand-alone load or grid-connected load.

Nowadays, the study of the wind simulator includes the development of both the software and hardware. For most of the WTS, the prime mover (replace the real wind) is the most commonly used motor to drive the generator by direct coupling or belts. The digital signal processing (DSP) hardware is used to control the software.[3] As an alternative, micro-controller or programmable logic control can also be used to control the software.[4] Some of the controllers involve simulation software like MATLAB-Simulink for flexible control scheme. [5]-[6] The industrial inverter drive may be used to drive the motor system and obtain adjustable speed drive system. The power rating of the wind turbine simulator is from $1 \mathrm{~kW}$ to $20 \mathrm{~kW}$.[7]

However, the motor that can produce the actual wind has not been developed in order to produce varying wind speed that feeds the wind energy to the wind turbine for actual electricity production. This is difficult to achieve due to the extensive radius of the wind turbine which requires expansive surface for the wind velocity to produce appropriate amount of wind needed to produce electricity. Moreover, the noise generated will also be excessive and thus, not suitable for laboratory use. 
The idea of Prakatwutthichon.P[8] and D.S.Dolan[9]was todevelop the wind turbine tester in the open loop wind tunnel by using the axial fan as the actual wind generator. Moreover, the stack of the axial fan was applied to medium power wind turbine testing. FeiDuan[10] andWeikang Du[11] continuously developed the microwind turbine tester in the laboratory. The wind tunnel is of great importance such that it could help the researchers to design and develop the wind blade, the control techniquesand the monitoringsystem. In addition to that, the wind tunnel can be used to test the efficiency of any type of micro-scale wind turbine. The objective of this study are as follows:(1) Design and construct the wind turbine simulator based on the adjustable actual wind speed.(2) Investigate the wind distribution. (3) Apply the design to test the power output of the micro-wind turbine in the laboratory of the Faculty of Engineering and Architecture of Rajamangala University of Technology Suvarnabhumi, Thailand.

\section{LITERATURE REVIEW}

Neammanee. B et al.[7] presented a wind turbine simulator which uses induction motor driven by the invertor to obtain the speed control functionality. The motor was directly coupled to the shaft of the $1 \mathrm{~kW}$ DC generator. They used the Van De Hoven spectrum to control the speed drive system which in turn was controlled by a DSP.

R. Ahshan et al.[12] developed a Programmable Logic Controller (PLC) controller which is able to control small-scale wind turbine simulator (WTS). The small-scale wind turbine simulator was used in the Energy System Laboratory of Memorial University of Newfoundland. The WTS used the directly coupled DC motor to drive the induction generator and connected the AC power to the low-voltage utility grid.

Weihao.Hu et al.[13] presented the wind turbine simulator by using permanent magnet synchronous motor (PMSM) driven by vector control technique. The torque of motor was controlled by a micro-controller-based module inverter. This system obtains the wind speed and calculates torque of a real wind turbine by using the wind turbine characteristics and the rotation speed of PMSM. Subsequently, the output torque of the PMSM can be regulated by controlling the stator current and frequency. The inverter driving the PMSM can work like a real wind turbine.

Moore.I et al.[14] presented the hardware of the wind turbine simulator that connects the output of the wind turbine generator to the utility grid by 2 back-to-back convertors. The $1 \mathrm{~kW}$ synchronous generator was applied in this hardware. The AC to DC converter was controlled via an embedded control system and driven by a DCmotor. A basic control method for the power transfer was implemented in MATLAB/Simulink and then used to drive a converter PWM via a dSPACE interface.

Paepen.S et al. [15] showed the small wind turbine simulator which was controlled by LabVIEW via the industrial invertor drive (SIEMENS). The wind energy pattern was generated by LabVIEW. The PC-based monitoring system can display torque, power, wind speed and other parameters from the wind turbine simulator.

D.S. Dolan et al. [9] developed the wind tunnel for lab-scale wind turbine testing. They used the tube axial duct fan with 5 horse power (hp) induction motor driven by a Siemens inverter. The fan diameter was 42 inches driven by the belts. The test employed the use of a $400 \mathrm{~W}$-wind generator. The results found that the tunnel was able to generate wind speed up to $14 \mathrm{~m} / \mathrm{s}$ at the cross sectional area as large as $3.25 \times 3.25$ feet $^{2}$.

Abo - Khalil et al.[3] developed the wind turbine simulator by using square cage induction motor with direct coupling to the induction generator. The DSP-TMS320C33 was applied to control the torque of the motor drive and the generator produced electrical power for the utility grid.

Karakasis.N et al. [4] presented the wind turbine simulator for laboratory use. The simulator comprises of a $5.5-\mathrm{kW}$ induction generator which is driven by a variable speed drive AC motor and a PLC that simulates the wind turbine power speed characteristics. The motor drive is connected to the generator by shaft direct coupling method. The performance of the Wind Energy Conversion System can be tested at the laboratory in dynamic and steady-state wind condition as well as in stand-alone and grid connected configurations.

PhlearnJansuya et al. [5] applied MATLAB/Simulink to represent the model of WTS. This model can simulate the operating parameters of the DC Motor driving the induction generator. In addition to that, the model is able to identify the mechanical power and torque for varying wind velocity and identify the power flow of an induction generator into the load.

Liyong Yang et al.[16] developed the novel WTS that uses $11.5 \mathrm{~kW}$ PMSM to drive the generator by employing real time programming with the DSP interface. The novel WTS can control the torque of generator comparable to the natural wind.

CiprianVlad et al. [17] presented the real-time replication of a stand-alone wind energy conversion system. This system uses the 3 phase induction motor to directly drive the shaft of the 3 phase permanent magnet synchronous generator (PMSG). The load current of the generator was controlled by theDC chopper. 
Ki-Yong et al. [18] designed and constructed the $20 \mathrm{~kW}$ of WTS by using AC motor with torque control inverter to drive the wind turbine generator by coupling belt. The AC motor drove the pitch control blade of the generator. This system can simulate with comparable similarities as the $3 \mathrm{MW}$ wind turbine.

Fernando Martinez et al. [2] developed the open-loop wind turbine emulator (WTE). The model consists of the AC Motor drive with direct coupling to an induction generator. The speed of the DC Motor was controlled by 3 phases AC- to - DC convertor. The output of the generator is connected to the grid via a grid-tie inverter. The emulator can be adjusted to the power curve of commercial wind turbine.

P.Prakatwatthchon et al. [8] developed the prototype of the wind turbine tester with variable velocity pattern. The wind generator uses $0.37 \mathrm{~kW}$ AC motor which was driven by invertor drives. They studied the air flow pattern in different conditions which include the incorporation of honeycomb, the incorporation of the nozzle, and without both the honeycomb and nozzle. The results found that the best wind distribution and wind speed is in the case without honeycomb and nozzle.

FeiDuan et al. [10] developed the wind field by setting up arrays of axial fans and investigated its uniformity and turbulence intensity. The wind field consisted of 9 independently controllable axial fans in a $3 \times 3$ stacked square configuration. The dimensions of the effective wind output area are $3.76 \times 3.76 \mathrm{~m}^{2}$. The system can be used to generate model wind speed up to $9.53 \mathrm{~m} / \mathrm{s}$. Subsequently, the system also investigated the dynamic response of a 1:50 scale model OC3 spar floating wind turbine concept which was designed for the operational depth of $200 \mathrm{~m}$. In this study, the rotor was allowed to rotate freely with the wind speed, and this approach eliminated some of the undesirable effects of controlling wind turbine rotational speed

Weikang Du et al. [11] from the State Key Laboratory of Ocean Engineering in Shanghai, China investigated the $1 / 50$ th scale model wind turbine based on a NREL-5MW. The wind field generator was axial fans in a $3 \times 3$ stacked square configuration. The model blade was designed at zero pitch angles and further tested in FAST, a fully coupled simulation tool. A model test was conducted using the optimized blade geometry.

\section{METHOD}

\section{A. DetermineMotor and Inverter size}

The author defined the wind-generating machinesuch that it can generate the maximum wind speed at $9 \mathrm{~m} / \mathrm{s}$. The fan blade diameter is 0.56 meter. The wind flow rate $(\mathrm{Q})$ can be determined by equation (1). The power at the rotor disk (equation (2)) gives the maximum power available in the wind[19]. But practically, wind turbine extracts only $20 \%-40 \%$ of the energy from the wind. Therefore, the mechanical power developed by the wind turbine in such situations can be estimated by using equation (3). The maximum power coefficient is around 0.1 -0.4. [20] The power of motor drive could be determined by equation (4). Lastly, the overall efficiency is determined by equation (5).

$$
\begin{aligned}
& Q=A V \\
& P=\frac{1}{2} \rho Q V^{2}=\frac{1}{2} \rho A V^{3} \\
& P_{\text {mech }}=\frac{1}{2} \rho A V^{3} C_{p} \\
& P_{\text {motor }}=\frac{P}{0.5 \times 0.5} \\
& \eta_{\text {overall }}=\frac{P_{\text {out }}}{P} \times 100 \%
\end{aligned}
$$

$\rho$ is the air mass density $\left(1.2 \mathrm{~kg} / \mathrm{m}^{3}\right.$ at $\left.25^{\circ} \mathrm{C}\right)[8]$, $\mathrm{A}$ is the area of rotor disk, $\mathrm{A}=\pi \mathrm{R}^{2}\left(\mathrm{~m}^{2}\right), \mathrm{V}$ is the wind flow $\operatorname{speed}(\mathrm{m} / \mathrm{s}), Q$ is the wind flow rate $\left(\mathrm{m}^{3} / \mathrm{s}\right), P$ is the wind Power $(\mathrm{W})$ and $\mathrm{P}_{\text {motor }}$ is the power of motor $(\mathrm{W})$, $\mathrm{P}_{\text {mech }}=$ mechanical power of the wind turbine $(\mathrm{W}), \mathrm{C}_{\mathrm{p}}=$ maximum power coefficient, $\mathrm{P}_{\text {out }}=$ =lectrical power output of the wind turbine including the rectifierand convertor(W), $\eta_{\text {overall }}=$ overall efficiency of the wind turbine.

The author estimatedthat the efficiency of motor and invertor is around $50 \%$, and the efficiency of the wind turbine generator is estimated to be $50 \%$. This is because there are electrical losses and mechanical losses in the motor and generator. To determine the rated power of motor, equation (4) will be used. The calculation result of the motor's power is $347.12 \mathrm{~W}$. The rating of motor that was used in this project was SUNTEC-MH-B3; 3 phase $/ 220 \mathrm{~V} / 50 \mathrm{~Hz} / 375 \mathrm{~W} / 1450 \mathrm{rpm}$. The inverter, acting as a frequency converter,was used to drive the three phase induction motor. The author chose a single phase $220 \mathrm{~V} / 50 \mathrm{~Hz}$ input inverter with a 3 phase $220 \mathrm{~V}$ output. The motor model is DELTA VFD-EL. This model is suitable to control and drive theSUNTEC-MH-B3 motor. Thespecification of the motor, the invertor and the blade of wind simulatorare as shown in Table I. 
TABLE I. Specification of the wind simulator.

\begin{tabular}{|c|c|c|c|c|c|c|c|c|c|c|}
\hline \multicolumn{5}{|c|}{ Motor } & \multicolumn{2}{|c|}{ Blade } & \multicolumn{4}{|c|}{ Inverter } \\
\hline \multicolumn{5}{|c|}{ Model : Suntec MH-B3 } & \multicolumn{2}{|c|}{ Model :--- } & \multicolumn{4}{|c|}{ Model :DELTAVFD-EL } \\
\hline Phase & $\begin{array}{c}\text { Voltage } \\
\text { V) }\end{array}$ & $\begin{array}{c}\text { Frequency( } \\
\mathrm{Hz})\end{array}$ & $\begin{array}{l}\text { Power( } \\
\text { W) }\end{array}$ & RPM & Number & $\begin{array}{l}\text { Diameter( } \\
\mathrm{cm})\end{array}$ & $\begin{array}{c}\text { Phase(I/ } \\
\text { O) }\end{array}$ & $\begin{array}{c}\text { Voltage } \\
\text { (V) }\end{array}$ & $\begin{array}{c}\text { Current( } \\
\text { A) }\end{array}$ & $\begin{array}{c}\text { Frequency }(\mathrm{H} \\
\mathrm{z})\end{array}$ \\
\hline 3 & 220 & 50 & 375 & 1450 & 4 & 56 & $(1 / 3)$ & 220 & 4.2 & 50 \\
\hline
\end{tabular}

B. Research Procedure

This study will action by follow the flowchart (Fig.1.) such as;(1)to design CAD and drawing of the wind turbine simulator, and adjustable wind-generating machine. (2)To assembly and improve the wind turbine simulator. (3) Test the motor'soperating by using the frequency convertor drive. (4) Determine relationship between the powers of motor vs wind speed by varies the frequency. (5) Investigate the wind distribution and wind pattern of the wind-generating machine. (6) Install a $100 \mathrm{~W}$ micro-wind turbine generator and (7) determine the power output and efficiency of micro-wind turbine generator.

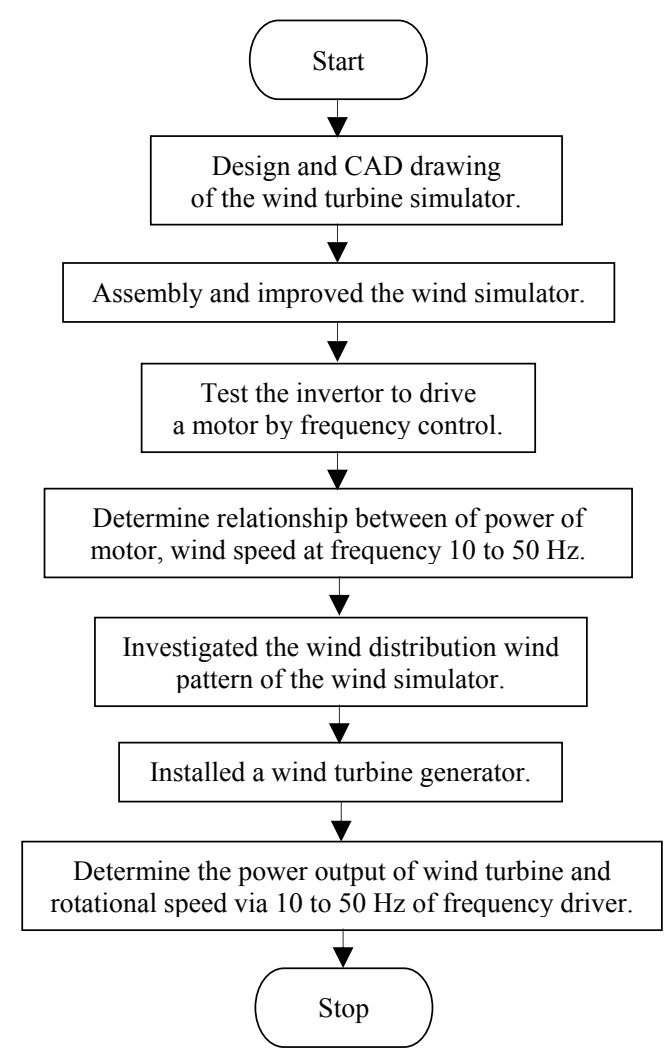

Fig.1.Researchprocedure

\section{Design and CAD drawing of the wind turbine simulator}

The concept idea of the author was realized into a CAD drawing and will be built to a prototype in the next step. The CAD drawing of the wind turbine simulator was developed by using SolidWorks2012.The drawings of an axial fan, an adjustable speed wind generator, a 100-Watts six blademicro-wind turbine and aluminium frame with the arcylic wall is as shown in Figure 2. Moreover, the base-plate of the micro-wind turbine canbe removed and switched to test a different one. 

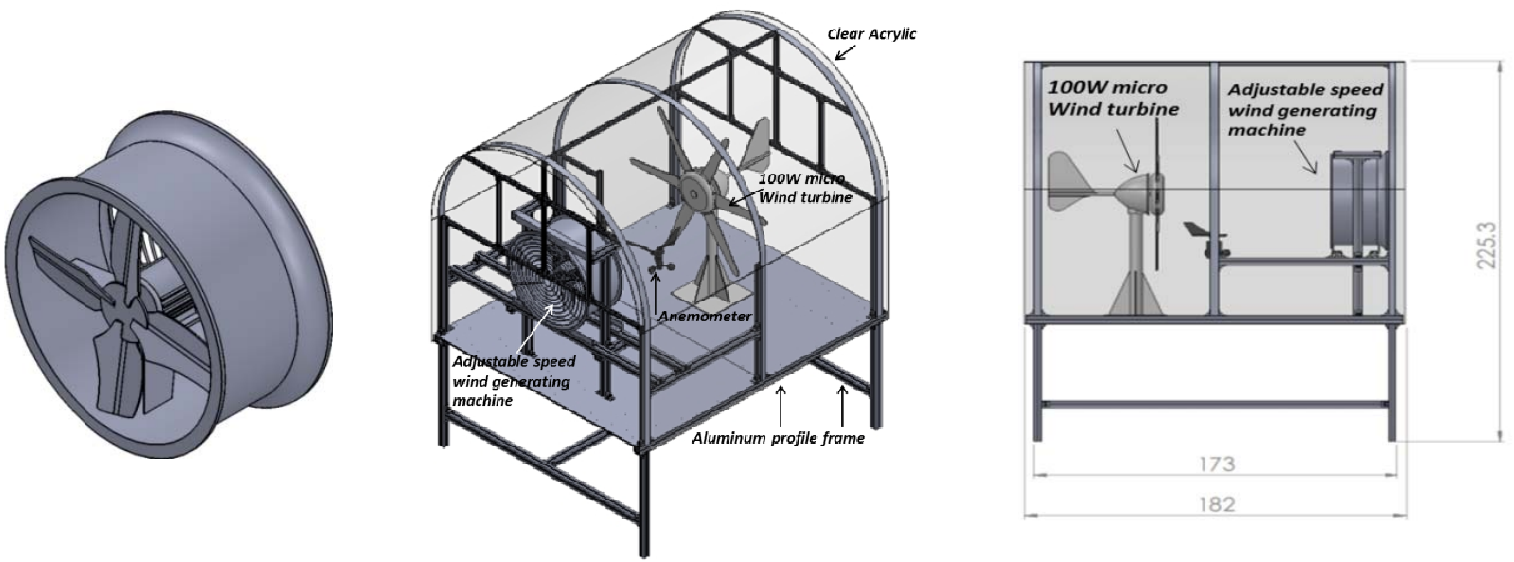

Fig.2.CAD design of the velocity adjustable wind turbine simulator

\section{Assembly of the wind turbine simulator}

The wind turbine simulator was built and improved for suitable use in the laboratory. Prior studies behind the theory of the local wind characteristic, the principles of building an open -loop wind tunnel, axial fan and the speed control was conducted by the author. Subsequently, the designwas made based on the data obtained by the author as follows: the profile frame is constructed with aluminum, the wall was made from the acrylic with the thickness of $4 \mathrm{~mm}$, the axial fan (motor with blade) and tube was installed on the square aluminum profile frame and the wind turbine generator was installed on the opposite side. The specification of the micro-wind turbine is as shown in table II. In conclusion, the dimension of the wind turbine simulator was $151.6 \mathrm{~cm} \times 182 \mathrm{~cm} \times 225.3$ $\mathrm{cm}(\mathrm{W} / \mathrm{L} / \mathrm{H})$ as shown in TableII.

TABLE II. The specification of the micro-wind turbine generator.

\begin{tabular}{|c|c|c|c|c|c|c|}
\hline \multicolumn{2}{|c|}{ Blade } & \multicolumn{3}{c|}{ Generator } & \multicolumn{2}{c|}{ Wind speed(m/s) } \\
\hline Number & Diameter(cm) & Type & Po(W) & Vo DC(V) & Cut-in & Rated \\
\hline 6 & 99 & PMSG & 100 & 12 & 2.5 & 14 \\
\hline
\end{tabular}

\section{E. Wind and Electrical Data Measurement.}

The wind speed was measured by an anemometer (AM 4836C), situated in front of the blade of motor (D= $56 \mathrm{~cm}$ ) in the horizontal plane. The measurement distant from the blade is $60 \mathrm{~cm}$. The interval space between the measurement points was $2 \mathrm{~cm}$, in total 39 point were measured as shown in Figure 6 . The experiment was conducted at the frequency between 10 to $50 \mathrm{~Hz}$. (with a10 $\mathrm{Hz}$ interval)

The AC input of invertor was measured by the power meter (Fluke 435) to obtain the AC input power. The DC output voltage and current from the micro-wind turbine was measured by the multi-meter Kyoritsu (KEW1009).Lastly, the rotational measurement was conducted with the digital techno meter OEM model HS2234. Each data was collected for three times (at an interval of 10s) and the average was determined.

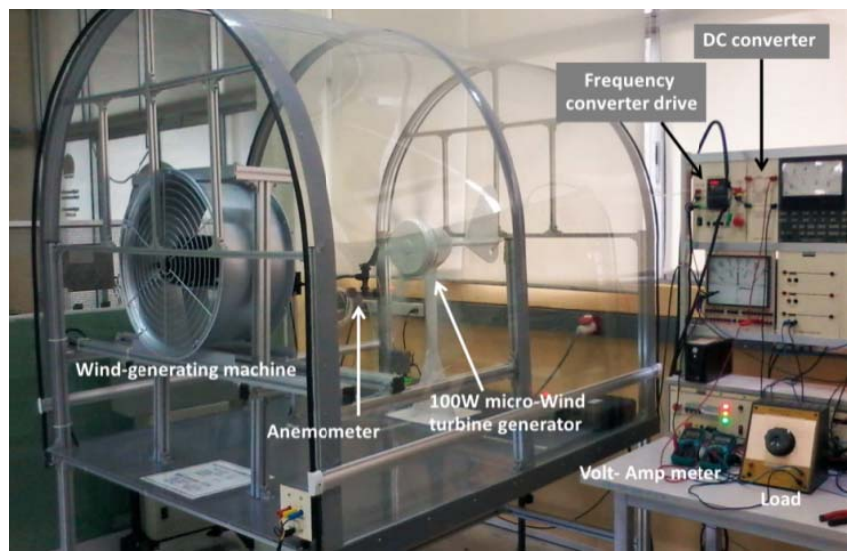

Fig.3.The experimental setupto determine the power output of the micro-wind turbine 


\section{RESUlts}

\section{A. The operation of the wind simulator.}

In order to test the designof the wind simulator, the author established the relationship between the power of motor, wind speed and frequency.Figure 4 shows the experimental diagram. The 3-cups anemometer was installed at the center of the motor shaft ata distance of $60 \mathrm{~cm}$. The actual wind speed can be adjusted by the frequency convertor drive (Invertor) which is in an intervalfrom $0 \mathrm{~Hz}$ to $50 \mathrm{~Hz}$. Figure 6 shows that the maximum wind speed which is equal to $9.33 \mathrm{~m} / \mathrm{s}$, when the frequency of the rotation of motor is at a maximum of $50 \mathrm{~Hz}$. At this point the power consumed by motor is about $252 \mathrm{~W}$. The wind speed can be adjusted linearly from 0 to $9.33 \mathrm{~m} / \mathrm{s}$ as shown by the blue line on the graph in Figure 5. The input power of motor drive increases proportionally with the frequency of themotor.

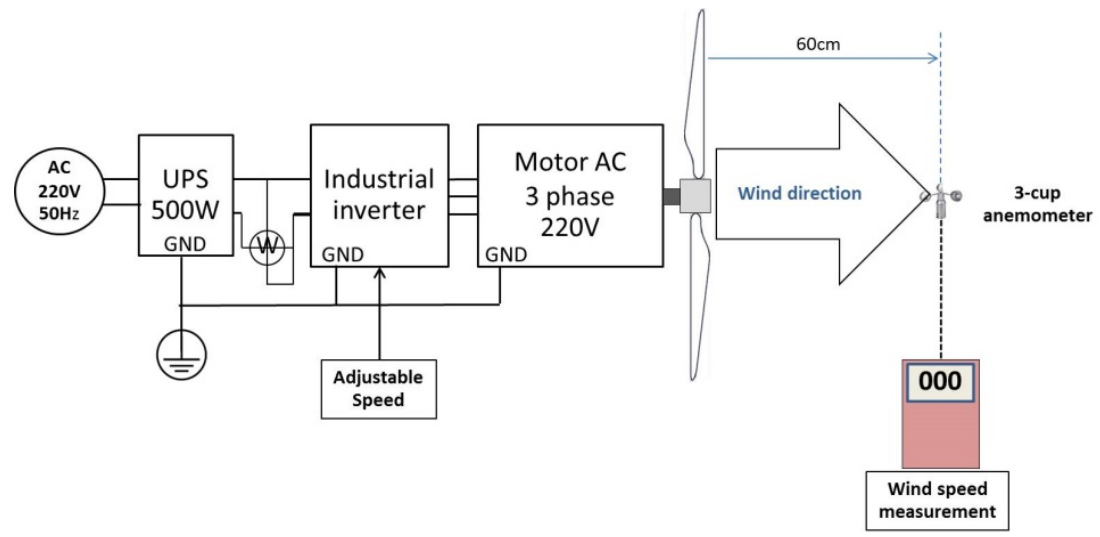

Fig.4.The experimental diagram.

Power of motor, wind speed vs frequency

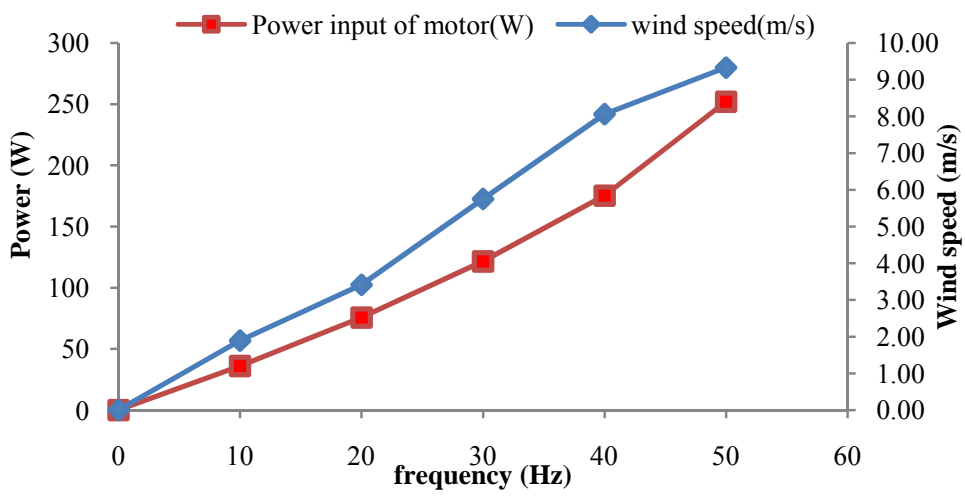

Fig.5. Scatted plot of power input of motor VS Wind speed.

\section{B. Investigatingthe wind distribution.}

To investigate the pattern of the wind distribution that can be generated by the actual wind simulator, the experimental setup was performed as shownin Figure 6. The anemometer set up is the same as the firstexperiment. The wind measurement position is on the XY line from $-40 \mathrm{~cm}$ to $+40 \mathrm{~cm}$, with an interval step of $2 \mathrm{~cm}$. The set up wind speed are at five levels from $10 \mathrm{~Hz}$ to $50 \mathrm{~Hz}$ with an interval step of $10 \mathrm{~Hz}$. The result of the wind distribution for each frequency is as shown in Figure 7. 


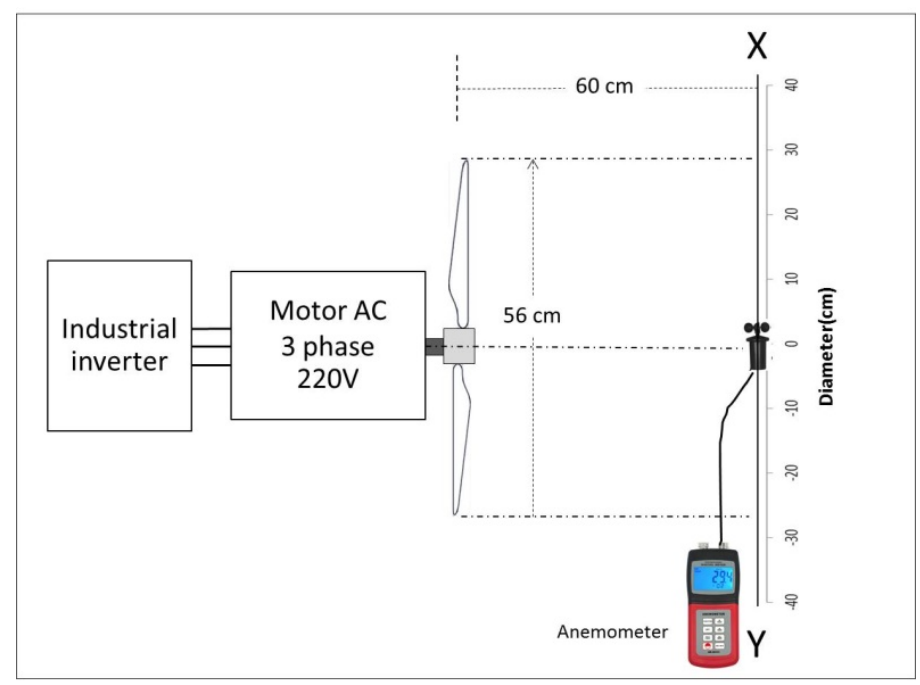

Fig.6.The wind distribution experimental setup

From figure 7, when the rate frequency of the motor is at $50 \mathrm{~Hz}$, the wind speed was constant but with a slight fluctuation $(9.33 \mathrm{~m} / \mathrm{s}$ to $8.6 \mathrm{~m} / \mathrm{s})$ when $\mathrm{XY}+28$ to $-28 \mathrm{~cm}$. (the measurement position is equal to the diameter of the blade). However, the wind speed will immediately decrease at the measurement position of more than \pm 28 $\mathrm{cm}$. For example, the wind speed was only about $2 \mathrm{~m} / \mathrm{s}$ at $\pm 40 \mathrm{~cm}$ measurement position. If the speed of the motor was decreased, the wind speed will be decreased as well. The graph displays the wind speed at $50 \mathrm{~Hz}$, $40 \mathrm{~Hz}, 30 \mathrm{~Hz}, 20 \mathrm{~Hz}$, and $10 \mathrm{~Hz}$. The distribution of air flow always covered the cross section area of the fan blade. The air flow distribution is constant at all frequencies, although, the wind speed will decrease at the end of the blade diameter as shown in Figure 8.

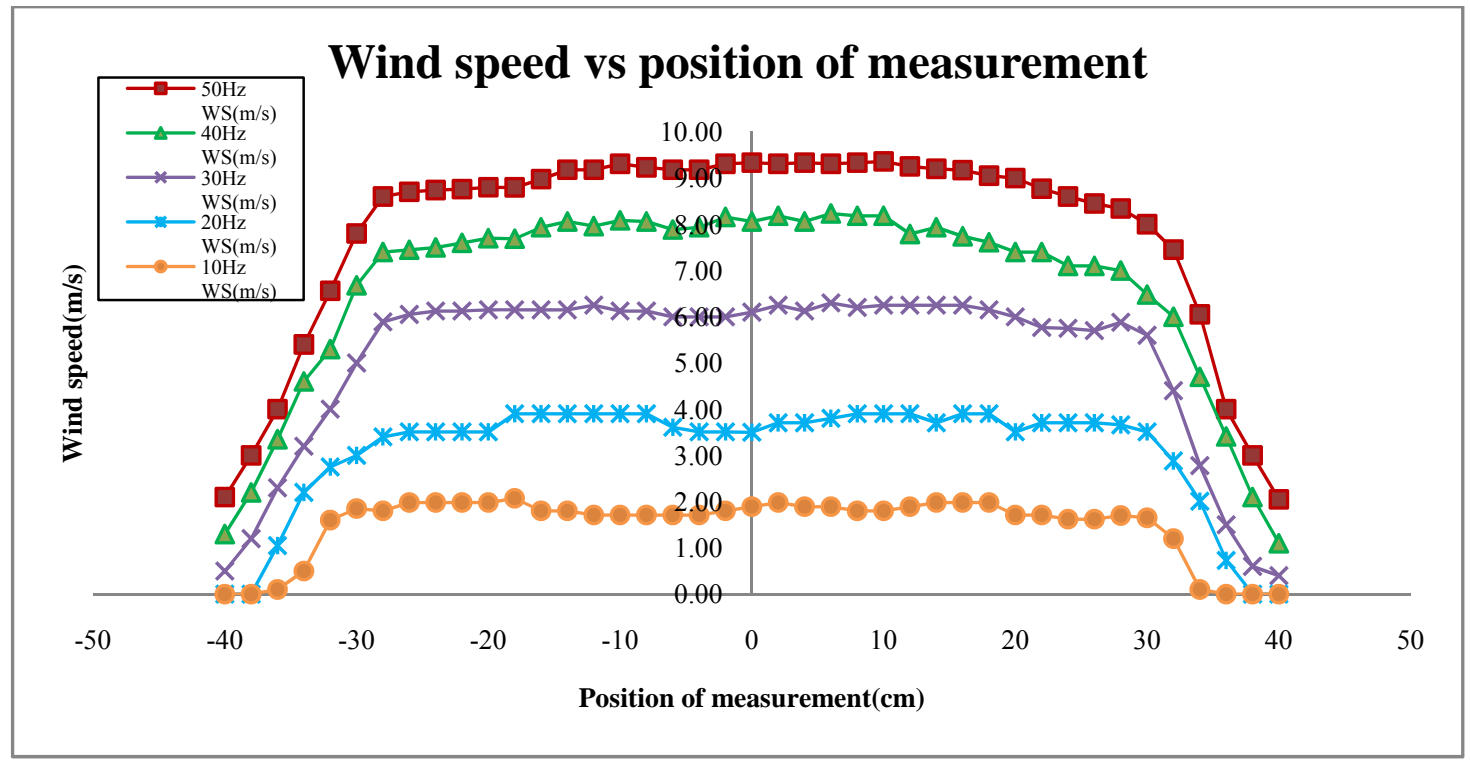

Fig.7.The wind speed distribution of the measurement position 


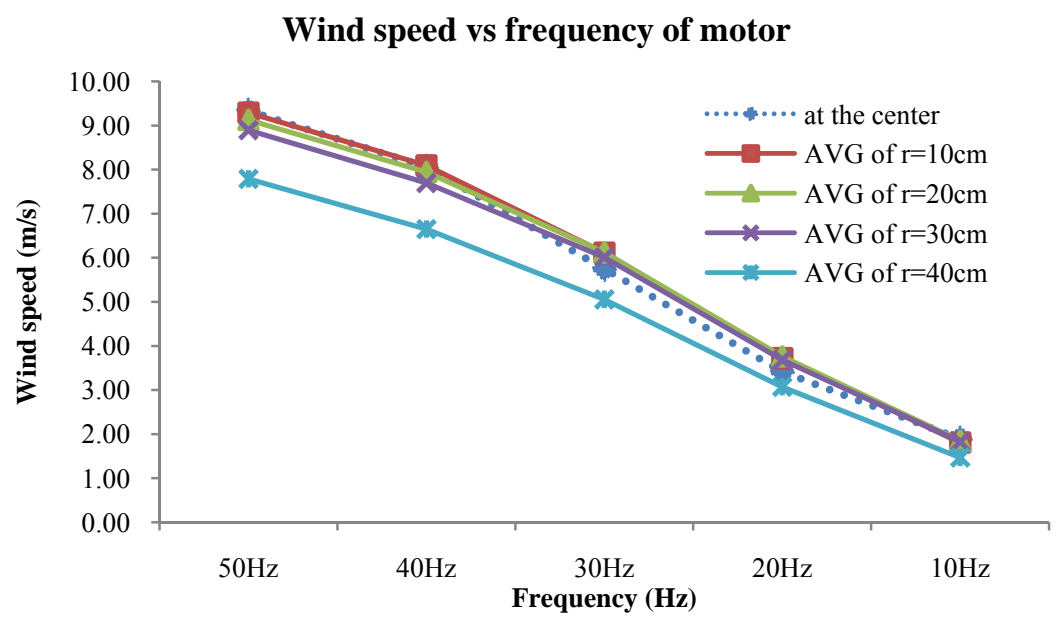

Fig.8. The average wind speed at difference radius of the blade

\section{Determining the power output of wind turbine under test.}

The setup has been connected as the experimental diagram shown in Figure 9. The setup disconnects the Rload to obtain the no-load test status. The speed of wind simulator was adjusted at the frequency from $10 \mathrm{~Hz}$ to $50 \mathrm{~Hz}$ (at the step interval of $10 \mathrm{~Hz}$ ). The rotational speeds of motor and wind turbine generator were then measured. The graph of the rotational speed with respect to the frequency is as shown in Figure 10. It was shown that the rotational speed will increase linearly with the frequency. The maximum speed of the motor was $1333.2 \mathrm{rpm}$ and the generator maximum speed was $469.6 \mathrm{rpm}$. When the generator takes a full-load, the speed of generator was reduced at all frequencies. The comparison of no-load and full-load speed of the wind turbine generator is as shown in Figure 11.

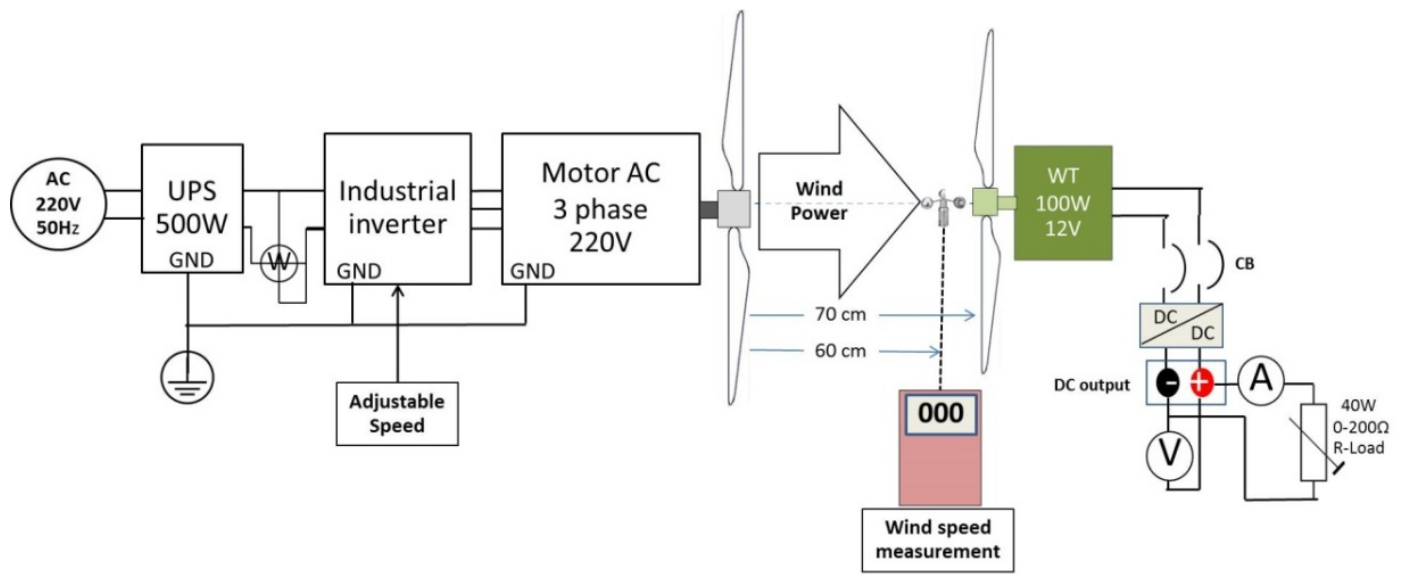

Fig.9.The experimental diagramto determine the power output of the wind turbine generator

\section{Rotational speed vs frequency}

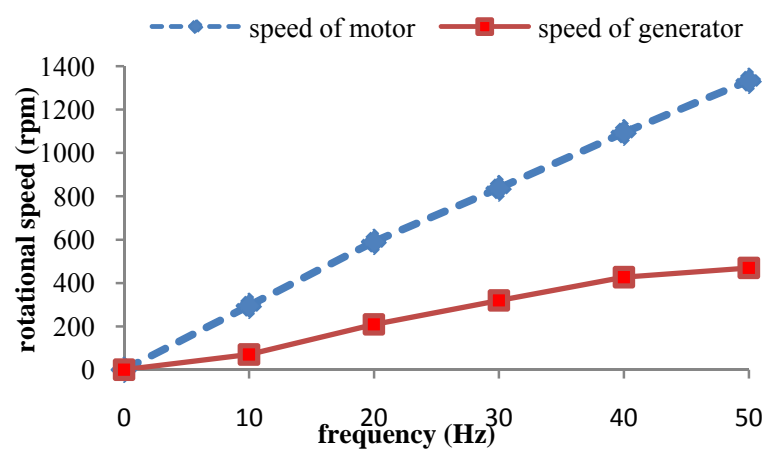

Fig.10. Rotational speed vs frequency (no-load) 


\section{Generator speed vs frequency of motor}

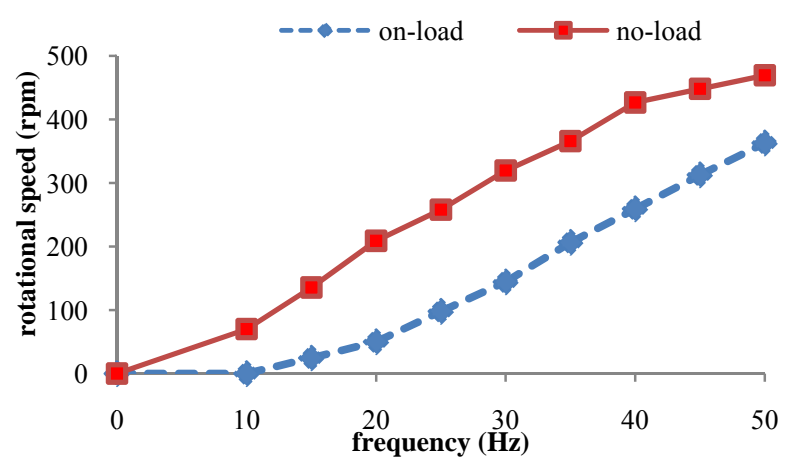

Fig.11. Generator speed vs frequency

According to Figure 9, the generator power was determined by connecting the resistive load at the output of generator. The maximum speed of motor was set up to be $\mathrm{f}=50 \mathrm{~Hz}$, resulting in the wind speed of around 9.33 $\mathrm{m} / \mathrm{s}$. Subsequently, the load resistance was adjusted until the maximum power transfer was generated to the

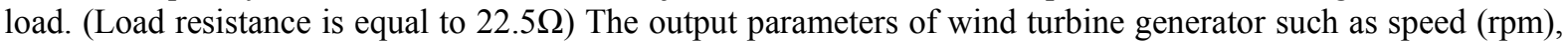
voltage (V), current (A) were measured and recorded. Finally, the power (W) was also calculated. The wind turbine generator produced the maximum power of about $7.40 \mathrm{~W}$ at $363 \mathrm{rpm}$ of the turbine speed or $7.40 \mathrm{~W}$ when the wind speed was $9.33 \mathrm{~m} / \mathrm{s}$. The graph of the generator power, rotational speed and the wind speed is as shown in Figure 12.

\section{Generator power, rotational speed vs wind speed}

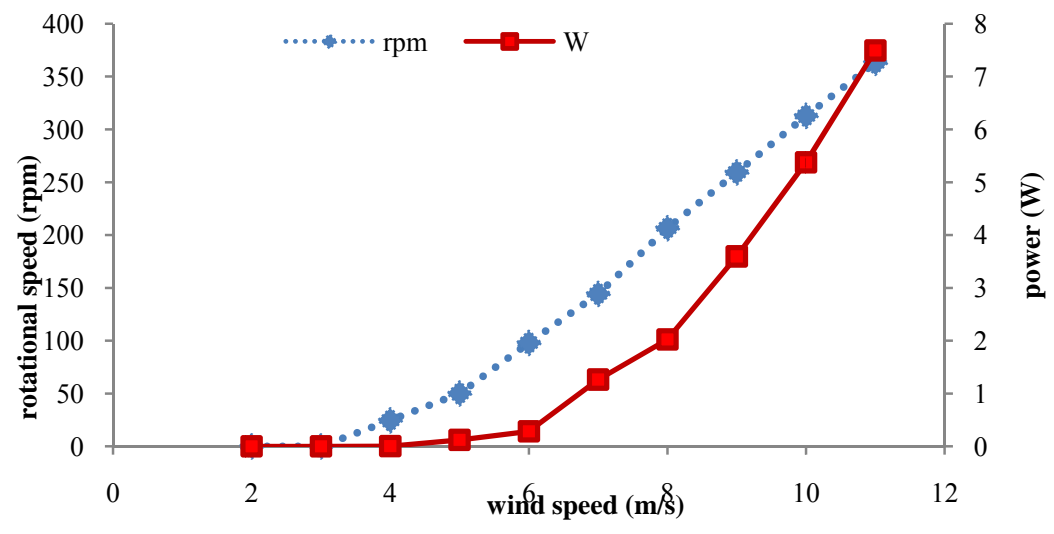

Fig.12.Generator output power and rotational speed vs wind speed

\section{Discussion}

The axial fan with the frequency convertor drive was used to drive the wind-generating machine and to adjust the wind speed. This technique is appropriate for controlling the wind speed and wind pattern and is consistent with the study of Prakatwuttichon.P.[8] and FeiDuan [10]. This technique can manually control or insert the other automatic wind pattern control.The nature of the air flow from the wind-generating machine was distributed in a cylindrical shape(Figure 13) with a diameter of $0.56 \mathrm{~m}$. The air flow distribution was rather constant at all frequency, in accordance with the study of Prakatwuttichon.P.[8]

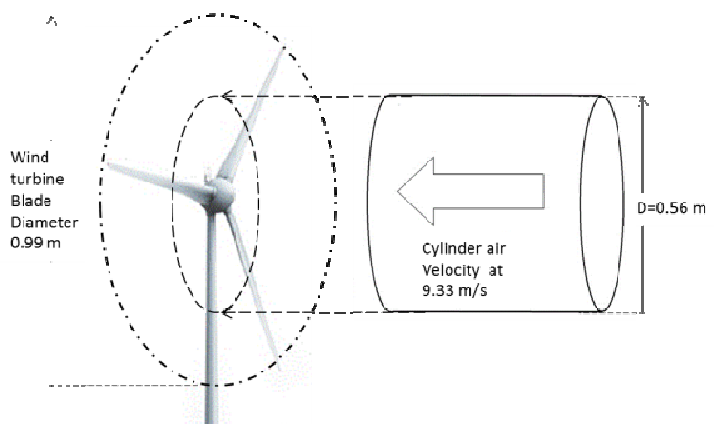

Fig.13. The diameter of cylindrical air flow and diameter of the wind turbine blade 


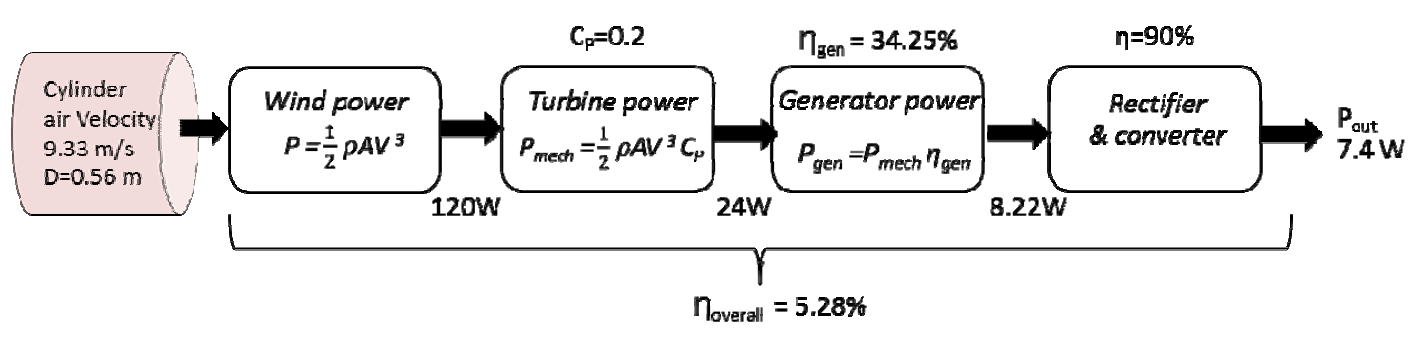

Fig.14. Energy flow diagram and efficiency of the micro-wind turbine under testing condition.

After testing with the 100-Watts micro-wind turbine by using the wind turbine simulator, the maximum output power of the wind turbine generator is about $7.4 \mathrm{~W}$ at $9.33 \mathrm{~m} / \mathrm{s}$. The power of the wind was calculated by equation (2), resulted in $120 \mathrm{~W}$. The calculated mechanical power of the wind turbine (equation (4) at $\mathrm{C}_{\mathrm{p}}=0.2$ ) is about $24 \mathrm{~W}$. (Figure 14). The overall efficiency of this study is equal to $5.28 \%$ at $\mathrm{C}_{\mathrm{p}}=0.2$ when the wind velocity is $9.33 \mathrm{~m} / \mathrm{s}$ (equation 5). The author defines the efficiency of rectifier and converter to be $90 \%$, and calculated the generator efficiency which is equal to $34.25 \%$. (Figure 14) The result is in accordance with the study of Mohamed Y.Z. [21] where a centimeter-scale micro wind turbine $(\mathrm{D}=2.6 \mathrm{~cm})$ was tested at a wind velocity of $6.5 \mathrm{~m} / \mathrm{s}$. The overall efficiency of the wind turbine at $\mathrm{Cp}=0.1$ is about $3.42 \%$ and conforms to the study of Carli et al. [22] whose overall efficiency of the micro-wind turbine $(\mathrm{D}=6 \mathrm{~cm})$ was about $5 \%$, and $\mathrm{Xu}$ et al. [23] whose 4-blade micro-wind turbine $(\mathrm{D}=7.6 \mathrm{~cm})$ has an overall efficiency of about $7.6 \%$.

The losses of the wind energy system consisted of mechanical loss (roughness of the blade, friction and windage loss) and electrical losses (Copper loss, hysteresis loss, and rectifier \& converter losses). It is sensible, when compared to the study of Mohamed Y.Z. [21], Carli et al. [22] , and Xu et al. [23].

Consequently, the main cause that contributed to the low power output of the wind turbine is the cylindrical shape of the air from the blade of motor which has a diameter $(0.56 \mathrm{~m})$ less than the diameter of the wind turbine blade $(0.99 \mathrm{~m})$ (Figure 13). This shows that the diameter of the motor blade influences the power output of the wind turbine. Thus, the output power of the micro-wind turbine under test could be increased by increasing the diameter of the fan blade of the wind-generating machine. This method can increase the diameter of the cylindrical air flow to blade of the wind turbine.

However, the adjustable speed of the open-loop wind turbine simulator is suitable for use in the laboratory. The authors have to develop the closed-loop control of the wind speed with PC-based monitoring system in the future.

\section{ConCLusion}

The axial fan with a three phase induction motor driven by invertor was used to obtain adjustable wind velocity for the wind turbine simulator. The fan was able to produce various wind speed where the maximum wind speed is around $9.33 \mathrm{~m} / \mathrm{s}$. The distribution of air flow always covered the cross section area of the fan blade. The air flow distribution was constant at all frequencies. The wind speed was decreased at the end of the fan blade diameter.The wind turbine simulator could be applied to test the micro-wind turbine. The micro-wind turbine could generate the output power graph resembling the power curve of the wind turbine's manufacturer.

The open-loop adjustable speed wind turbine simulator has a great benefit for using in the laboratory.The wind generating machine could apply for design the new wind turbine and the blade, to test the aerodynamics of the vehicle model or the building model. Moreover,could apply to evaluate the control response or mathematical model of the wind energy system. Finally, this idea was realization and appropriate for apply tothe research and experiments of the architecture and engineering students.

\section{REFERENCES}

[1] (2016) The GWEC website.[Online]. Available:http://www.gwec.net/global-figures/wind-energy-global-status/

[2] Fernando Martinez, L. Carlos Herrero, Santiago de Pablo, "Open loop wind turbine emulator,"Renewable Energy, Volume 63, Pages 212-221.Mar.2014.

[3] Abo-Khalil, A.G.,"A new wind turbine simulator using a squirrel-cage motor for wind power generation systems,” Power Electronics and Drive Systems (PEDS), IEEE Ninth International Conference on,2011, vol., no., pp.750,755

[4] Karakasis, N.; Mesemanolis, A.; Mademlis, C.,"Wind turbine simulator for laboratory testing of a wind energy conversion drive train," Power Generation, Transmission, Distribution and Energy Conversion (MEDPOWER 2012), 8th Mediterranean Conference on, 2012 , vol.,no., pp.1,6

[5] PhlearnJansuya, YuttanaKumsuwan, Design of MATLAB/Simulink Modeling of Fixed-pitch Angle Wind Turbine Simulator, Energy Procedia, Volume 34, Pages 362-370.2013.

[6] Mohammad Monfared, HosseinMadadiKojabadi, HasanRastegar,"Static and dynamic wind turbine simulator using a converter controlled dc motor," Renewable Energy, Volume 33, Issue 5, Pages 906-913.May.2008.

[7] Neammanee.B, SompornSirisumrunnukul, SomchaiChatratana. "Development of Wind Turbine Simulator for Wind Generator Testing.’International Energy Journal 8.21-28.2007.

[8] Prakatwutthichon, P., Uangpairoj, P., and Chamniprasart, K. "Design and Prototyping Wind Turbine Tester with Variable Velocity Pattern." The 8th South East Asian Technical University Consortium (SEATUC) Symposium. March 4-5, 2014. Johor Bahru, Malaysia.4 pp. 
[9] D. S. Dolan, D. Zepeda and T. Taufik, "Development of wind tunnel for laboratory wind turbine testing," North American Power Symposium(NAPS), 2011, Boston, MA, 2011, pp. 1-5.doi: 10.1109/NAPS.2011.6025188

[10] FeiDuan, Zhiqiang Hu, J.M. Niedzwecki, "Model test investigation of a spar floating wind turbine," Marine Structures, Volume 49, Pages 76-96, ISSN 0951-8339.Sep.2016.

[11] Weikang Du, Yongsheng Zhao, Yanping He, Yadong Liu, "Design, analysis and test of a model turbine blade for a wave basin test of floating wind turbines," Renewable Energy, Volume 97, Pages 414-421, Nov.2016.

[12] R. Ahshan, M.T. Iqbal, George K.I. Mann, “Controller for a small induction-generator based wind-turbine,” Applied Energy, Volume 85, Issue 4, Pages 218-227. Apr. 2008.

[13] Weihao Hu; Yue Wang; Xianwen Song; Zhaoan Wang, "Development of wind turbine simulator for wind energy conversion systems based on permanent magnet synchronous motor," Electrical Machines and Systems, ICEMS 2008, International Conference on, 2008, vol., no., pp.2322,2326.

[14] Moore, I.; Ekanayake, J., "Design and development of a hardware based wind turbine simulator," Universities Power Engineering Conference (UPEC), 2010 45th International, 2010, vol., no., pp.1,5.

[15] Paepen, S.; De Koker, K.; Adams, P.; Coussens, P., "Industrial drive based wind simulator for small wind turbine optimization," Clean Electrical Power (ICCEP), 2011 International Conference on ,2011, vol., no., pp.786,790.

[16] Liyong Yang; Sufang Yan; Zhigang Chen; Weipeng Liu, "A novel wind turbine simulator for wind energy conversion systems using an permanent magnet synchronous motor,” Electrical Machines and Systems (ICEMS), 2013 International Conference on , 2013, vol., no., pp.2156, 2158.

[17] CiprianVlad, AntonetaIulianaBratcu,IulianMunteanu, SilviuEpure .Real-time replication of a stand-alone wind energy conversion system: Error analysis Electrical Power and Energy Systems 55,562-571.2014.

[18] Ki-Yong Oh, Jae-Kyung Lee, Hyung-Joon Bang, Joon-Young Park, Jun-Shin Lee, B.I. Epureanu, "Development of a $20 \mathrm{~kW}$ wind turbine simulator with similarities to a 3 MW wind turbine," Renewable Energy, Volume 62, Pages 379-387.Feb. 2014.

[19] A. Saravanan, C. Karthikeyan and A. Samuel ."Exergy Analysis of Single Array Wind Farm Using Wake Effects," Engineering, Vol. 3 No. 9, 2011, pp. 949-958.doi: 10.4236/eng.2011.39117.

[20] Keith M. Sunderland, MahinsasaNarayana, GhanimPutrus, Michael F. Conlon, Steve McDonald, "The cost of energy associated with micro wind generation: International case studies of rural and urban installations," Energy, Volume 109, Pages 818-829, 15 Aug. 2016. ISSN 0360-5442, http://dx.doi.org/10.1016/j.energy.2016.05.045.

[21] Mohamed Y. Zakaria, Daniel A. Pereira, Muhammad R. Hajj, "Experimental investigation and performance modeling of centimeterscale micro-wind turbine energy harvesters," Journal of Wind Engineering and Industrial Aerodynamics, Volume 147, Pages 5865,Dec. 2015.ISSN 0167-6105, http://dx.doi.org/10.1016/j.jweia.2015.09.009.

[22] D. Carli, D. Brunelli, D. Bertozzi and L. Benini, "A high-efficiency wind-flow energy harvester using micro turbine," SPEEDAM 2010, Pisa, pp. 778-783.2010.doi: 10.1109/SPEEDAM.2010.5542121

[23] Xu, F., Yuan, F., Liu, L., Hu, J., and Qiu, Y. "Performance Prediction and Demonstration of a Miniature Horizontal Axis Wind Turbine.” J. Energy Eng., 10.1061/(ASCE)EY.1943-7897.0000125, 143-152.2013.

\section{AUTHOR PROFILE}

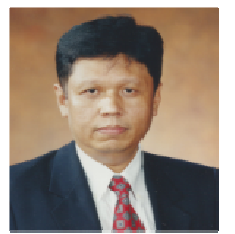

Napat watjanatepin professor (associate) in electrical engineering education b.s.tech.ed.(electrical engineering) institute of technology vocational education, thailand (1985) m.s.tech.ed (electrical technology) king mongkut's institute of technology north bangkok, thailand (1991) research interest photovoltaic energy system, pc based monitor system, power electronics, engineering education publication 36 of the books (in thai), 10 of national journals, 19 of national conferences, 7 of international journals, and 35 of international conferences.

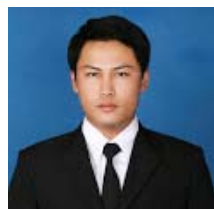

SUVINAI SODAJAROEN Education B.Eng (Industrial Engineering) Rajamangala University of Technology Lanna, Thailand (2009) M.Eng (Manufacturing Engineering) Rajamangala University of Technology Thanyaburi, Thailand (2015)Research interest CAD design, Production engineering, Material and Welding Engineering 